\title{
The Analysis and Design of Automatic Beverage Vending System based on UML
}

\author{
Yindi Dong \\ School of Information Engineering, Chongqing City Management College, Chongqing
}

\begin{abstract}
UML is a standard modeling language, which is easy to express, powerful and universal. At the same time, it can support the software development process from the demand analysis. Using UML modeling mechanism, which can be visual representation and construction of system model for all the development process of the application software system based on UML. We design the use case diagram, class diagram, timing diagram, etc.
\end{abstract}

\section{Introduction}

In recent years, the automatic beverage vending system get the majority of consumers as a kind of new intelligent products, with simple operation, convenient service. It has developed rapidly in the United States, Japan and other countries since the listing, and now has been widely spread in 45 countries. At the same time, it is developing rapidly as an emerging industry in China. Today, in the airport, subway, shopping malls, parks and other places, it is not difficult to find the automatic beverage vending system. If the vending system market is fully developed, its prospects are very impressive, when China's automatic beverage vending system will develop into a huge industry. In this paper, we have the requirement analysis and modeling by UML modeling language for automatic beverage vending system. UML modeling tools with high efficiency model, which can be designed to facilitate change, strong expansibility and easy maintenance of automatic beverage vending system.

UML (Unified Modeling Language) is used to describe the structure of software system and business modeling graphical language, which is a standard language with description, visualization, and documentation of object-oriented product development system. It has obtained excellent software engineering method, which is recognized in the field of modeling of complex systems with new ideas and new methods and the new technology into the field of software engineering and by amending the found problems in the practical application. It has become a recognized industry standard object oriented technology. Its scope is not only limited to object oriented analysis and design, but also supports the whole process of software development. IBM Rational Rose and MS Visio are UML tools. UML provides 9 kinds of rich and powerful model for the design and development of software system: use case diagram, activity diagram, class diagram, object diagram, state diagram, sequence diagram, collaboration diagram, component diagram and deployment diagram, which introduces the system model using the static model and dynamic model. It describes the development projects from different perspectives and different stages of software development, and can be a good understanding.

\section{The modeling of automatic beverage vending system based on UML}

\subsection{System requirements analysis phase}

Requirements analysis includes the establishment of business models and user requirements analysis in the problem domain. First of all, we need to get the requirements, the use cases that describe the system functions, business processes or clear text, which are observed from the outside of the system. In UML, the use case diagram and some simple class diagrams can be used to describe the user's functional requirements. The use case diagram is used to describe a type of document, which shows participants who complete a process using a system when the time sequence. The use case diagram displays a set of case system, the relationship between the use case and participants. 
The function description of automatic beverage vending system: to provide customers with the purchase of goods; to verify the legitimacy of coins; to prompt abnormal situation (goods sold, the change inappropriate, etc.); to find change. Specific analysis is as follows:

The main purpose of the beverage vending system is to allow customers to buy drinks. Customers insert coins into it and choose what they want. If not, the vending system will give customers a message that there is not this beverage. Ideally, customers see this message, then the display will show other drink immediately, and the system must also be provided to retrieve money for the customer. It should give customers two options: let customers choose other drink and provide the drink to customers or refund money. If the change in the storage is run out, a message should be displayed to tell the user that the appropriate change is needed. The main work for the supplier and the payee is as follows: to supply goods timely and provide the conditions for handling abnormal situation. The supplier opened the machine and front desk shelf, then filled with various kinds of beverage on the shelves and put the change in it. Finally he put the front shelf and locked it. The pre-condition of the use case is the passing of a time interval, and the post-condition is that the supplier placed a new drink for sale.

\subsection{System use case diagram}

The use case model of a system is composed of a plurality of use case diagram, use case diagram of the main components are use cases, actors and system. The simple icon elements describe the actors and the system interaction and the function of the system. Use cases drive the method of system analysis and system design, which has become the mainstream of object-oriented method. First of all, we should analyze and determine the activity and the case in order to establish the case model during the development of a software system. Use case model is the link of developers to communicate with customers.

Buying drink module is part of the beverage vending system, which is mainly responsible for providing customers with the purchase of goods. From the previous analysis, we know that there are three actors for the system, customers, suppliers and payee. We could get the actors from the above requirements analysis. Customer: get the item you want to buy from a vending system. Supplier: responsible for the sales of beverage system. Payee: responsible for collecting the money from the vending system regularly.

Through the above analysis, we can get the system use case diagram as shown in Fig. 1.

\subsection{System class diagram}

Class diagram is used to express the relationships between classes in a system. The model element that is allowed in the class diagram is only the class and its relationship. There are several classes of graphs in a system. The steps of constructing class diagram: research and analysis the problems, determine the system requirements; determine the class, make clear the meaning and responsibility of class, make sure the attribute and operation; express the relationships between classes with the association, generalization, aggregation, combination; adjust and refine the relationships, such as naming conflicts, repetitive function problems; draw class diagram and add the appropriate instructions. There are many classes involved in the automatic beverage vending system, and there is a cooperative relationship between them. We show the relationship between classes with the beverage vending system, the front desk, the coin record, the distributor and the transaction record. As shown in Fig.2.

\subsection{System dynamic model}

The dynamic model is used to describe the dynamic behavior of the system, and shows the dynamic interaction between the object and the system at different times during the system operation. In the UML, the dynamic model is established by using the time sequence diagram, collaboration diagram, state diagram and activity diagram. During the system analysis and design, we draw these graphics for the main use cases and objects in order to analyze the dynamic characteristics and behavior of the system.

Sequence diagram is used to describe the interactions between objects, and reveals the interaction of a specific scene. It is suitable for describing the time characteristics and time constraints in real-time systems, and the message is sent by the time. Collaboration diagram is also 
used to describe the interaction between system objects. Sequence diagram emphasizes time sequence of the operation between objects, and collaboration diagram emphasizes the relationship between the set of objects. Collaboration diagram and sequence diagram can be transformed into each other. The sequence diagram of beverage vending system is shown as Fig.3.

\section{System construction and testing}

In the construction or design phase, we transform the design phase of the class into some kind of object-oriented programming language code, and then complete the design class diagram of beverage vending system during the development cycle. We will get enough detail information about the generation of object definition field. When the design is mapped to the code, we write the definition and method of the class with the object-oriented programming language. In the program design phase, we still have to make many decisions to change design and continuous survey. Ideally, the whole structure and main design decisions should be completed before the encoding stage. There are many system testing methods, and different groups will take different UML diagram as the basic unit. The testing will be used the class diagrams and specifications, and the system test use case diagram to confirm the behavior of the system in line with the definition. For the automatic beverage vending system, the UML system modeling is the core work, the interface and the maintenance are the same important.

\section{Conclusion}

The above is a brief description of how to use UML modeling to develop the automatic beverage vending system. UML can provide flexibility and readability for the entire development process, and shows its strong function. UML combines the advantages of object-oriented modeling languages with a broad application prospects. Through the analysis, we can know that understanding the user needs and system design with the standard modeling language and tools can greatly improve the efficiency of application development. We hope that the wide application of automatic beverage vending system will provide more convenient and efficient service for people.

\section{References}

[1]Larman. The application of UML and model [M]. China Machine Press. 2016.5

[2]Meliir Page-Jones. UML object-oriented design. The Posts and Telecommunications Press. 2012.5

[3]Hu Hefen. UML object-oriented analysis and design. Tsinghua University press. 2012.5

[4]Xie Xing. UML foundation and Rose modeling practical guide. Tsinghua University press. 2011.1

[5]Grady Booch. James Rumbaugh. Ivar Jacobson. Unified Modeling Language User Guide. The Posts and Telecommunications Press. 2013.1

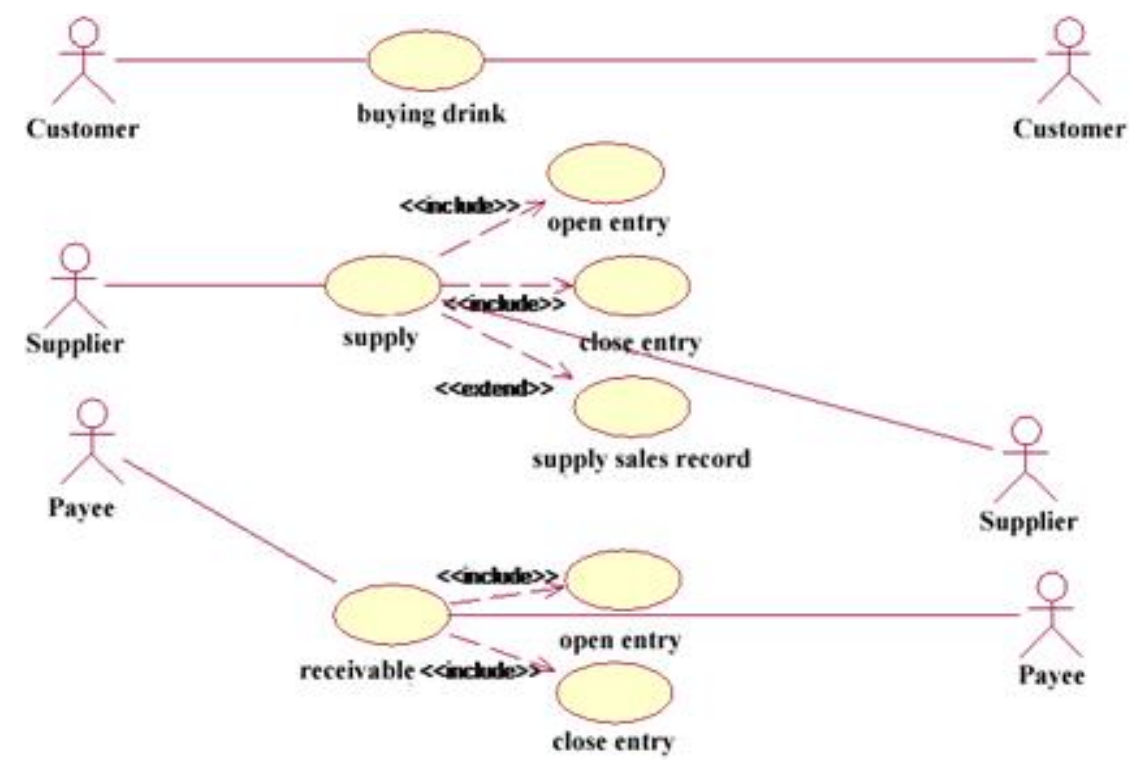

Fig.1. The use case diagram of automatic beverage vending system 


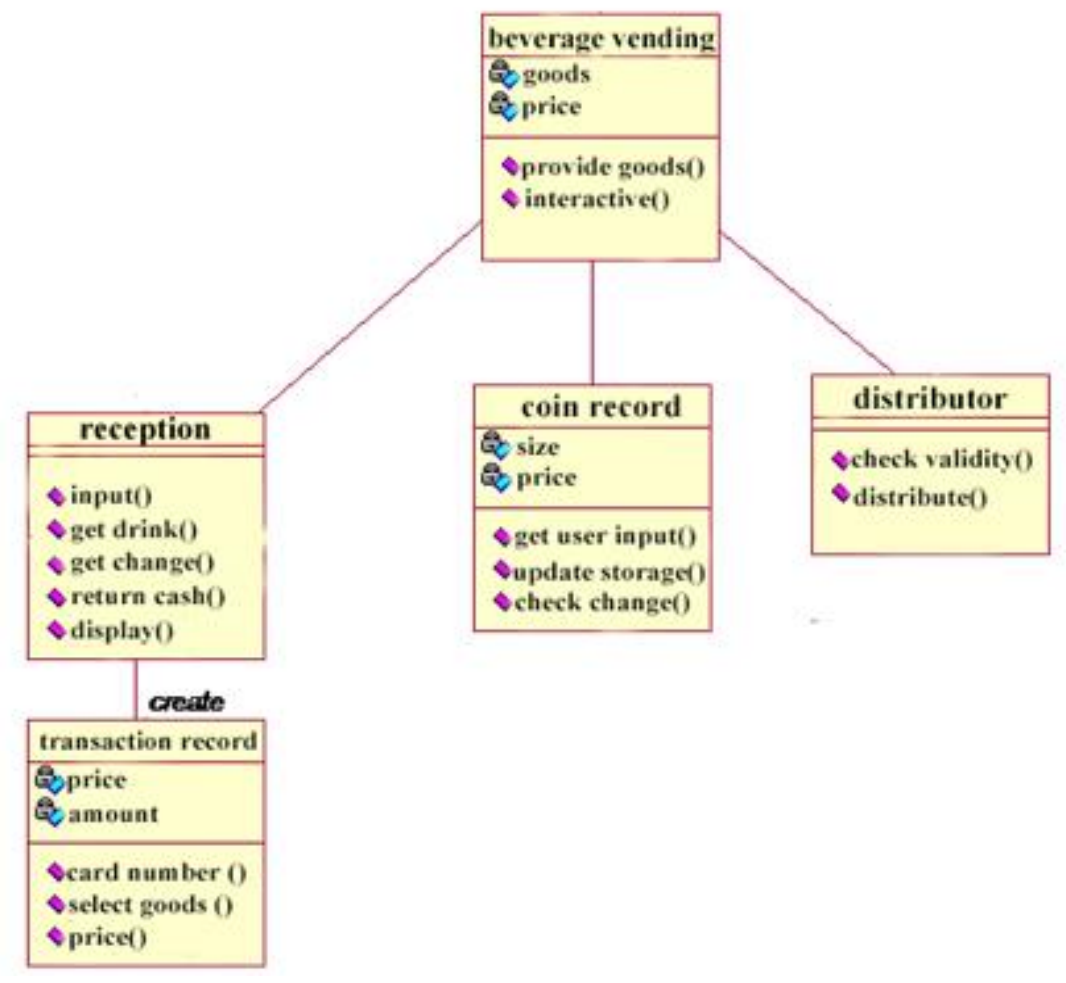

Fig.2. System diagram

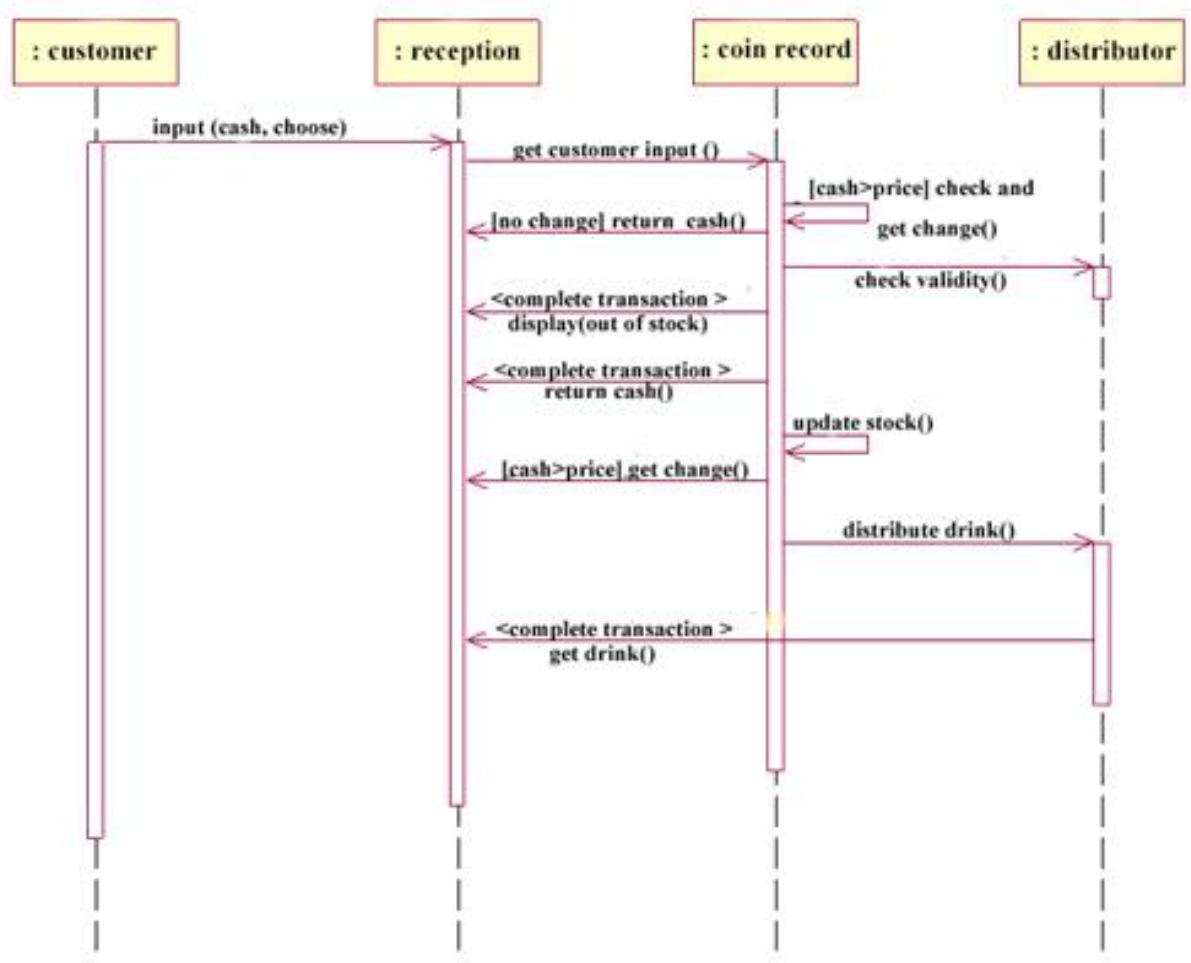

Fig.3. Sequence diagram of beverage vending system 